\title{
Conversion of Xylose Solution into Furfural at Atmospheric Pressure over the Solid Acid
}

\author{
Yuankui Wang ${ }^{\mathrm{a}}$, Huizhen Jia, Yunzheng Li, Qingshan Zhang, Hongquan Yin ${ }^{\text {b.* }}$ \\ Beijing Institute of Technology, Beijing 100081, China \\ awangyuankui12@163.com, bhqyin77@sohu.com
}

Keywords: Furfural; Xylose; Solid acid; Solvent extraction; Atmospheric pressure.

\begin{abstract}
This study mainly focused on the dehydration of xylose to furfural with green catalysis. The reaction was under atmospheric pressure, with the $\mathrm{SO}_{4}^{2-} / \mathrm{ZrO}_{2}$ as the catalyst plus an inorganic salt $(\mathrm{NaCl})$ as promoter. DMSO was used as a renewable extraction solvent in a biphasic system. The optimal catalytic reaction conditions were determined by single factor design. The results showed that the optimal catalytic reaction conditions were the following conditions: $30 \mathrm{~mL}$ of DMSO and $2 \mathrm{~g}$ xylose, $1 \mathrm{~g} \mathrm{NaCl}, 2.5 \mathrm{~g} \mathrm{SO}_{4}^{2-} / \mathrm{ZrO}_{2}$ and heating for $4 \mathrm{~h}$. It resulted in the maximum yield of $47.7 \%$. The experimental results showed that the preparation of furfural from xylose solution system with the solid acid catalyst, has the huge development potential. The addition of an inorganic salt $(\mathrm{NaCl})$ to the aqueous phase was shown to improve the yield of furfural.
\end{abstract}

\section{Introduction}

Rapidly growing worldwide energy demand has triggered a renewed interest in producing fuels from biomass to add to worldwide energy supplies[1].Because of the important applications in organic chemical industry, the synthesis of plastics, pharmaceutical, pesticides and so on, furfural and its production process have been a hot spot of research in the field of Biomass energy. Furfural, as one of the most promising green platform chemical compound, there is no synthetic route available for furfural production; therefore furfural is exclusively produced from renewable biomass resources by acid-catalyzed dehydration of pentoses (such as cornstalks and corncobs, oat and peanut husks, and other agricultural surpluses)[2].Conventional mineral acids, such as sulfuric acid, hydrochloric acid, phosphoric acid or super phosphate, are generally used as catalysts for the conversion of D-xylose to furfural. At $200-250^{\circ} \mathrm{C}$, over the catalyst of sulfuric acid, with the raw material of hemicellulose to produce furfural is commercially adopted method in the industry now. However, these mineral acids often lead to serious corrosion, safety problems, and difficulty in catalyst separation from the reaction products, excessive waste disposal, extensive side reactions, and loss of furfural yield due to long residence times[3].So the improvement of the chemical technology for the production of furfural therefore remains of great interest for the growth of furan-based chemical industries. Solid acids find a wide range of catalytic applications in oil and chemical conversion processes. Solid acid catalysis has attracted much interest both in fundamental and applied research because of its potential to generate significant economic and environmental benefits. Solid acids are widely used catalysts to promote the cracking of hydrocarbons. Therefore, it is hoped that solid acids can be used as catalysts to reduce the viscosity of heavy oil via mild cracking at the lower temperatures. Solid superacid refers to the acid with a strength corresponding to $\mathrm{H}+$. Zirconia promoted by sulfate groups or metal oxides are commonly used as solid superacids[4]. In this paper, D-xylose is catalytically converted to furfural, respectively by zirconia promoted by sulfate groups. We found that the sulfonic acid-functionalized ordered zirconia oxide is an effective catalyst for the dehydration of D-xylose to furfural, using the dimethylsulfoxide (DMSO) as the solvent. 


\section{Experimental}

Catalyst preparation. All starting materials were purchased from commercial sources and used as received.

Synthesis of $\mathrm{SO}_{4}^{2-} / \mathrm{ZrO}_{2}$. A $16.16 \mathrm{~g}$ sample of $\mathrm{ZrOCl}_{2} \cdot 8 \mathrm{H}_{2} \mathrm{O}$ (Wako Pure Chemical) was dissolved in $100 \mathrm{ml}$ of distilled water followed by addition of $\mathrm{NH}_{3}$ solution dropwise with stirring; the final $\mathrm{pH}$ of the solution was adjusted to 9. Gelation occurred on standing at room temperature about $72 \mathrm{~h}$. After that the solids were filtered and washed with water until a neutral filtrate and absence of chlorine ion was detected by $\mathrm{AgNO}_{3}$ tests. The solids were oven-dried at $65^{\circ} \mathrm{C}$ for $24 \mathrm{~h}$. Then grind into powder. And then the powder was stirred in an aqueous solution of $1.0 \mathrm{M} \mathrm{H}_{2} \mathrm{SO}_{4}$ for 24 hour. The catalyst was then separated from the suspension by means of vacuum filtration. After repeating this procedure three times, the solids were oven-dried at $65^{\circ} \mathrm{C}$ for $24 \mathrm{~h}$. Then grind into powder. Then heated to $550{ }^{\circ} \mathrm{C}$ in air overnight using a $3^{\circ} \mathrm{C} /$ minute heating ramp and calcined for 5 hours.

Catalytic dehydration conversion reaction of xylose to furfural. All reactions were performed under nitrogen and carried out in a biphasic reaction system system containing a reactive aqueous layer (mixture of water and a solid acid) and an extracting organic layer (using dimethylsulfoxide as the extraction solvent). All experiments were conducted using a glass flask, equipped with an agitator and a temperature-controlled electrical heating bath. In a typical experiment, $2 \mathrm{~g}$ xylose, $1 \mathrm{~g} \mathrm{NaCl}$, $2.5 \mathrm{~g} \mathrm{SO} \mathrm{SO}_{4}^{2-} / \mathrm{ZrO}_{2}, 30 \mathrm{~mL}$ of DMSO were poured into the reactor. The reactor was placed in a heating jacket until boiling for the time specified. After reaction, the reactor was cooled to room temperature by flowing air. The products in the DMSO or aqueous phases were analyzed using UV-visible spectrum. Authentic samples of xylose and furfural were used as standards, and calibration curves were used for quantification[5]. The two curves were showed below:

$$
\begin{aligned}
& \text { Fur }: Y=0.00734 X-0.02041 \\
& X y l: Y=0.0013 X-0.0450 \\
& Y: \text { absorbance, } X: \text { Concentration(ug/mL) }
\end{aligned}
$$

\section{Results and discussion}

Through analysis, there is no xylose in the organic phase, the conversion of xylose and the furfural yield was calculated as given below.

$$
\begin{aligned}
& \text { Conversion }=\frac{m_{\text {xylose }}-C_{\text {xylose }} \times V_{\text {aqueous }}}{m_{\text {xylose }}} \times 100 \% \\
& \text { yield }=\frac{M_{\text {furfural,obtain }}}{M_{\text {furfural, potential }}} \times 100 \%
\end{aligned}
$$

As we know, there are few studies about the reaction of xylose to furfural at atmospheric pressure. Only early scientists studied the dehydration of xylose with $\mathrm{HCl}[6]$. No studies about organic solvent extracting furfural from xylose with solid acid and inorganic salts at atmospheric pressure. And we chose dimethylsulfoxide as the organic extraction solvent because furfural had good solubility in it.

Because of the solid acid has high requirement to the reaction temperature, we set the temperature between $140{ }^{\circ} \mathrm{C}-160^{\circ} \mathrm{C}$. At this temperatuer, the solid acid has high reactivity. Effect of changing catalyst and temperature on furfural yield was researched under the following conditions: $30 \mathrm{~mL}$ DMSO, $2 \mathrm{~g}$ xylose, $1 \mathrm{~g} \mathrm{NaCl}$, heating for 4h.The best furfural yield achieved was $47.66 \%$ at $2.5 \mathrm{~g}$ $\mathrm{SO}_{4}^{2-} / \mathrm{ZrO}_{2} 160^{\circ} \mathrm{C}$ (Fig. 1). As we can see in the figure, when the catalyst is fixed, remarkable increases in furfural production were observed while the temperature increased. Effect of solid acid dose was also prominent. However, at the same temperature, the furfural yield decreased when the solid acid dose was very big. Figure 2 shows the effect of reaction time on the yield of furfural while using $\mathrm{NaCl}$ as the promoter. 


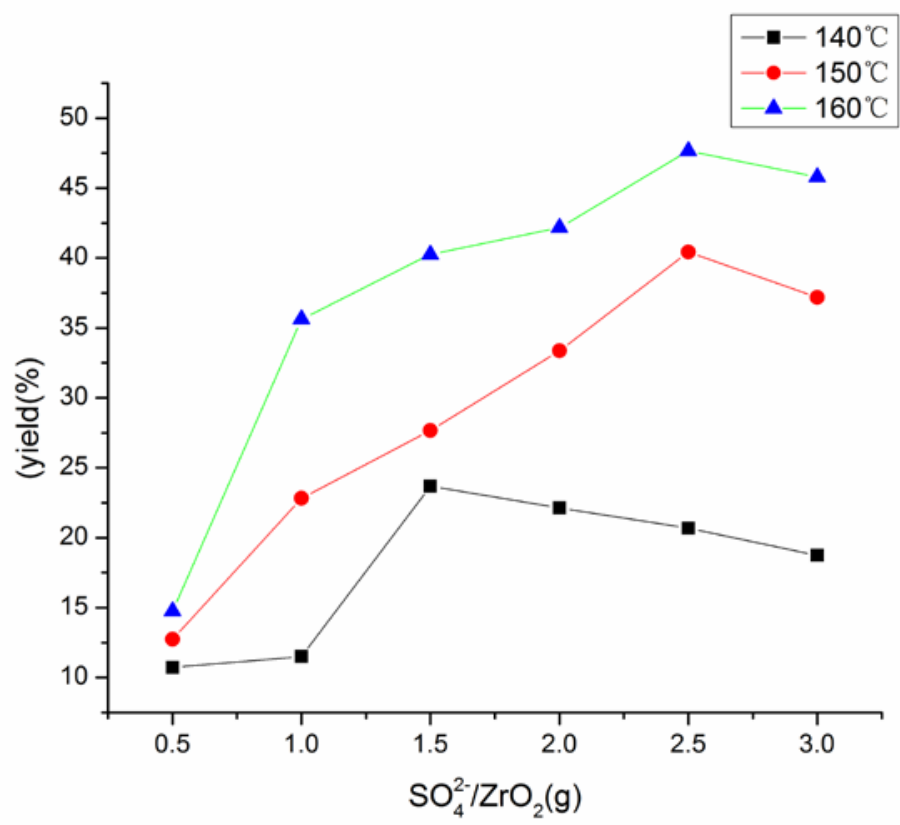

Fig. 1 Effect of changing catalyst and temperature on furfural yield under the following conditions: $30 \mathrm{~mL}$ DMSO, $2 \mathrm{~g}$ xylose, $1 \mathrm{~g} \mathrm{NaCl}$, heating for $4 \mathrm{~h}$.

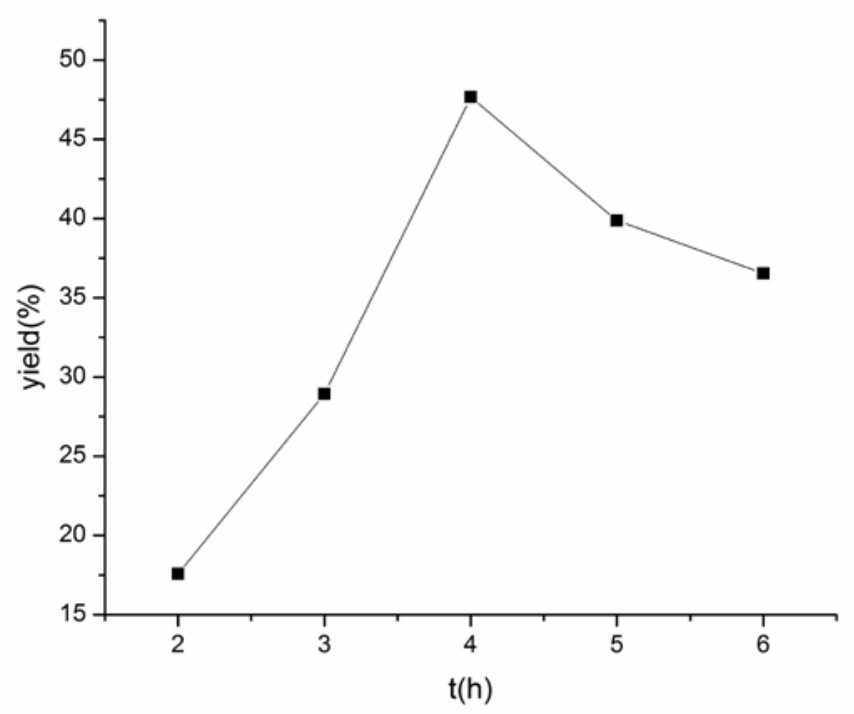

Fig. 2 Effect of heating time on furfural yield under the following conditions: 30mL DMSO, $2 \mathrm{~g}$ xylose, $1 \mathrm{~g} \mathrm{NaCl}, 2.5 \mathrm{~g} \mathrm{SO}_{4}^{2-} / \mathrm{ZrO}_{2}, 160^{\circ} \mathrm{C}$.

\section{Conclusion}

It has been demonstrated that the solid acid $\mathrm{SO}_{4}^{2-} / \mathrm{ZrO}_{2}$ is an active catalyst for the homogeneous liquid phase dehydration of xylose to furfural. The catalytic results depend on the reaction temperature, reaction time, the solid catalyst dose and the xylose dose. In this study, the maximum fufural yield was obtained under the following conditions: $30 \mathrm{~mL}$ DMSO, $2 \mathrm{~g}$ xylose, $1 \mathrm{~g} \mathrm{NaCl}, 2.5 \mathrm{~g}$ $\mathrm{SO}_{4}^{2-} / \mathrm{ZrO}_{2}, 160^{\circ} \mathrm{C}$, heating for $4 \mathrm{~h}$. 


\section{References}

[1] Mamman, A. S, Lee, J. M, Kim, Y. C, etc., Furfural: hemicellulose/xylosederived biochemical[J]. Biofuels, Bioproducts and Biorefining, 2008, 2 (5), p.438-454.

[2] Zhang, J, Zhuang, J, Lin, L., etc., Conversion of D-xylose into furfural with mesoporous molecular sieve MCM-41 as catalyst and butanol as the extraction phase[J]. Biomass and Bioenergy, 2012, 39, p.73-77.

[3] Moreau, C, Durand, R, Peyron, D, etc., Selective preparation of furfural from xylose over microporous solid acid catalysts[J]. Industrial Crops and Products, 1998, 7 (2), p.95-99.

[4] Dias, A. S, Lima, S. Pillinger, M., etc., Modified versions of sulfated zirconia as catalysts for the conversion of xylose to furfural[J]. Catalysis letters, 2007, 114 (3-4), p.151-160.

[5] Arnoldi, A, Corain, E. A., Scaglioni, L, etc., New colored compounds from the Maillard reaction between xylose and lysine[J]. Journal of agricultural and food chemistry, 1997, 45 (3), p.650-655.

[6] Rong, C, Ding, X, Zhu, Y, etc., Production of furfural from xylose at atmospheric pressure by dilute sulfuric acid and inorganic salts[J]. Carbohydrate Research, 2012, 350, p.77-80. 